\title{
BMJ Open Quality Improving waiting times in the orthopaedic outpatient clinic
}

\author{
Julia Street, ${ }^{1}$ Wajeeha Khan, ${ }^{2}$ Aureola Tong, ${ }^{3}$ Vasudev Shanbhag ${ }^{4}$
}

To cite: Street J, Khan W, Tong A, et al. Improving waiting times in the orthopaedic outpatient clinic.BMJ Open Quality 2017;6:e000067. doi:10.1136/ bmjoq-2017-000067

- Additional material is published online only. To view please visit the journal online (http://dx.doi.org/10.1136/ bmjoq-2017-000067).

Received 26 March 2017 Revised 2 May 2017 Accepted 13 June 2017

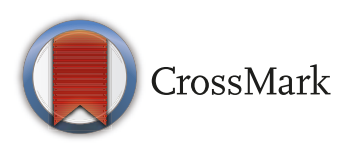

${ }^{1}$ Department of Trauma and Orthopaedics, Morriston Hospital, Morriston, UK ${ }^{2}$ Department of Medicine, Morriston Hospital, Morriston, UK

${ }^{3}$ Department of Trauma and Orthopaedics, University Hospital Wales, Cardiff, UK

${ }^{4}$ Department of Trauma and Orthopaedics, Nevill Hall Hospital, Abergavenny, UK

Correspondence to Julia Street, Department of Trauma and Orthopaedics, Morriston Hospital, Heol Maes Eglwys, Morriston, Swansea SA6 6NL, Wales, UK; juliastreet@doctors.org.uk

\begin{abstract}
Background Reducing waiting times for patients is a worthy goal for all healthcare professionals. The means and ability to carry out nerve conduction studies in the hand outpatient clinic has the potential to reduce waiting times between appointments for patients with upper limb neural compression.
\end{abstract}

Methods We assessed the pathway of patients presenting with upper limb neural compression in the Aneurin Bevan Trust. Overall, 115 patients were included, being assessed in four different patient pathway groups.

Results We found that by implementing a nerve conduction clinic, and then that of a one stop clinic, we were able to reduce the median waiting times from referral to surgical intervention, to 133 days.

Conclusion The introduction of nerve conduction clinics allowed the one stop clinic to be established, achieving the goal of reducing patient waiting times.

\section{PROBLEM}

Although the National Health Service is one of the great concepts of the twentieth century, as we move into the twenty-first century expectations and demands are increasing. The patients' experience of their encounters with the National Health Service is becoming increasingly important. Wait times are recognised as being a source of patient dissatisfaction in healthcare. Bleustein $e t a l^{1}$ found that every aspect of the patient experience correlated negatively with longer wait times. In their study of patients undergoing total knee arthroplasty surgery, Lizaur-Utrilla et $a l^{2}$ found that a waiting time longer than 6 months negatively influenced postoperative satisfaction, as well as patient-related outcome at 1 year following surgery.

Nevill Hall Hospital is part of the Aneurin Bevan University Health Board in South Wales, serving an estimated population of over $639000 .{ }^{3}$ In 2013, the Auditor General undertook a review of orthopaedic services across Wales, assessing each health board in turn, seeking to answer the question 'are orthopaedic services efficient, effective and economical?'. ${ }^{4}$ One of the conclusions of this report was that 'changes to the provision of outpatient services can help to reduce the number of times patients have to come to hospital. This could include hot clinics'.
On appointment as a consultant hand surgeon, the senior author (VS) was keen to improve patient services by seeking to reduce the waiting times and number of appointments associated with the outpatient clinics. Having seen one stop clinics run successfully in other health boards, it was suggested that they could be of benefit here.

As upper limb neural compression is a common condition presenting to upper limb clinicians, it was felt that improving management of these patients would be a sensible starting point. Carpal tunnel syndrome affects approximately 1 in 1000 of the population per year, ${ }^{5}$ with most patients eventually requiring surgical release of the transverse carpal ligament. Carpal tunnel release is indicated following the failure of conservative measurements and in cases of severe neural compression on nerve conduction testing. ${ }^{6}$ In their Cochrane Review of 2008, Verdugo et al reported that 'surgical treatment of carpal tunnel syndrome relieves symptoms significantly better than splinting. ${ }^{7}$

Following their assessment of postoperative outcomes in elderly patients undergoing carpal tunnel decompression, Leit et al concluded that "carpal tunnel release was unlikely to result in a total elimination of symptoms and complete restoration of function when performed in elderly patients with advanced nerve compression'. Therefore, treating patients with upper limb neural compression before they develop severe compression would aid in improving their clinical outcomes.

\section{BACKGROUND}

As previously stated, prolonged wait times contribute to patient dissatisfaction, with evidence to that effect. ${ }^{1}{ }^{2}$ The efficient management of all patients has the potential to save both health board and patient time. All projects start small and in this case improving the management of patients with upper limb neural compression was assessed. In many cases, nerve conduction studies can be a useful adjunct in guiding treatment. However, organising these tests can increase 
the waiting time between appointments, investigations and treatment. The means and ability to perform nerve conduction studies in the outpatient clinic could decrease wait times between appointments, as well as being a necessary first step in establishing a 'one stop clinic'.

One stop clinics have gained popularity in many specialties in recent years. As their name suggests, the patient is managed in one sitting, with one attendance for patient assessment, diagnostic testing and treatment. Clearly, this improves the times patients must wait and reduces the number of hospital visits. One stop clinics have already been established in gynaecology, ${ }^{9}$ urology, ${ }^{10}$ breast surgery, ${ }^{11}$ plastic surgery, ${ }^{12}$ ear nose and throat surgery, ${ }^{13}$ gastroenterology, ${ }^{14}$ care of the elderly ${ }^{15}$ as well as in orthopaedic surgery. ${ }^{1617}$

Ball $e t a l^{16}$ found that the use of one stop carpal tunnel clinics worked well. Reid $e t a l^{17}$ found high levels of patient satisfaction with the one stop clinic, with $95.35 \%$ stating they would recommend it to a friend or relative. It was felt that a similar strategy could be of benefit among our patient population.

\section{METHOD}

\section{Step 1: measurement}

Eighteen patients with neural compression syndromes were assessed in the outpatient clinic and then referred to the regional neurophysiology department for nerve conduction studies between 1 January 2013 and 30 June 2014. They were reviewed following the nerve conduction studies and subsequently underwent surgical decompression.

The times between initial clinical assessment, clinical review following nerve conduction studies and surgical intervention were collated. This was done through accessing the Clinical Work Station computer system that has been established in the Aneurin Bevan Health Trust. Patient demographics, appointments, investigations, clinic letters and operation notes are all contained on this database.

The time between initial clinical assessment and referral for nerve conduction testing to subsequent appointment following nerve conduction studies ranged from 58 to 300 days (median average 152 days).

The time from initial assessment in clinic to surgery ranged from 111 to 505 days (median average 345 days).

\section{Step 2: design}

In seeking to reduce the time patients were waiting for investigations and decisions, as well as number of appointments, it was felt that specific nerve conduction clinics in the same health trust would be of benefit and necessary if the future possibility of a one stop clinic was to be realised. There was much discussion among the senior members of the hand team about the pros and cons of such clinics.

First, the nerve conduction clinics were implemented so that patients seen by VS who required nerve conduction studies had these carried out by VS. The results would be available on the day of testing, and decisions about treatment could be made at that time. This involved an application for funding to purchase the necessary equipment and organisation of the training required to use the equipment.

Having set up the nerve conduction clinics, the concept of a one stop clinic was then a possibility. The Improvement Quality Training team were involved in discussions regarding the potential benefits of establishing such clinics. As one stop clinics were not taking place in the Trust, the department managers and day surgery nursing staff visited a similar clinic in another health board. This allowed them to see how the clinic was organised, how the patients were managed throughout the day and how the one stop clinic could benefit their own health board.

Further discussion was required to establish how the clinic would be run and how the most suitable patients could be selected for inclusion. Once this was all determined, the one stop clinic was then piloted among selected patients.

\section{Step 3: strategy and improvement cycles Cycle 1}

Nerve conduction clinics were commenced on 14 January 2014. Thirty patients were referred to the nerve conduction clinic between 14 January 2014 and 20 August 2014, and then subsequently underwent surgery. The time it took for these individuals to have the nerve conduction studies and surgery was then measured.

Not surprisingly, there were reductions in the amount of time that patients needed to wait for nerve conduction studies, with a range of 21-258 days (median 76 days) between initial clinical assessment and nerve conduction studies, which was the aim of implementing the nerve conduction clinic. However, despite the access to the local nerve conduction clinic, the time waited for subsequent surgery remained surprisingly prolonged, ranging from 120 to 776 days (median 409 days) between initial clinical assessment and surgery.

As the nerve conduction clinics were now available, this allowed for the introduction of one stop clinics, which would aim to try and reduce the overall waiting time and number of hospital visits.

\section{Cycle 2}

To ensure the most appropriate patients were selected for the one stop clinics, the patient referrals were triaged by the lead clinician for hand surgery and a list of potential patients was generated. Specific exclusion criteria included age under 25 years or over 80 years of age, treatment with anticoagulation, diabetes mellitus and patients with poor mobility. An administrator then picked patients from this list to be invited to the one stop clinic. A questionnaire was devised to be sent to the patients to ensure they were suitable for inclusion in the one stop clinic. If they were, they then received a letter explaining what the one stop clinic would involve and an information leaflet about their previously diagnosed condition. This was 
followed up with two phone calls from the administrator to ensure they were satisfied with the expected process. It was explained to them that should they wish to withdraw from this process, then they could do so at any stage.

The one stop clinic was rolled out as a pilot project on 15 July 2014. Waiting times from the one stop clinics between 15 July 2014 and 28 July 2015 were collated, along with patient-reported outcome measures.

Alongside the one stop clinic, nerve conduction clinics continued for patients unsuitable or unwilling to be managed in the one stop clinic. Waiting times for these individuals were collected between 5 November 2014 and 21 October 2015.

\section{RESULTS}

\section{Step 1: summary of results}

Overall, 115 patients were included, being assessed in four different patient pathway groups between 1 January 2013 and 21 October 2015 (see online supplementary appendix 1).

\section{Baseline measurements}

Eighteen patients who subsequently required neural decompression were referred to the regional neurophysiology department for nerve conduction studies between 1 January 2013 and 30 June 2014.

The waiting times at different stages were assessed, with the time between initial referral and subsequent appointment following nerve conduction studies ranging from 58 to 300 days (median average 152 days).

The time from initial assessment in clinic to surgery ranged from 111 to 505 days (median average 345 days).

\section{Cycle 1}

A further 30 patients were referred to the nerve conduction clinic between 14 January 2014 and 20 August 2014, and then went on to undergo neural decompression surgery.

The time from initial assessment in clinic to nerve conduction studies ranged from 21 to 258 days (median 76 days).

The time between initial clinical assessment and surgery ranged from 120 to 776 days (median 409 days).

\section{Cycle 2}

The one stop clinic commenced on 15 July 2014, and 37 patients were treated in this clinic between 15 July 2014 and 28 July 2015 . The total time they were required to wait between referral and one stop clinic date ranged from 66 to 213 days (median 133 days). There was no wait time between hospital visits, or further appointments, as it all took place on the same day.

Patients deemed unsuitable or declined inclusion in the one stop clinic continued to be reviewed in clinic, referred for nerve conduction studies and then listed for surgery if indicated. Thirty patients were managed in this way between 5 November 2014 and 21 October 2015.
The time from initial assessment in clinic to nerve conduction studies ranged from 2 to 223 days (median 51 days).

The between initial clinical assessment and surgery ranged from 13 to 434 days (median 260 days).

Clearly, there are outliers in all groups, which skews the results. In some cases, it is not clear why certain individuals waited longer than others; this may be due to delays on the part of either the patient or the hospital. The implementation of clinic-based nerve conduction studies made it possible to establish the one stop clinic, which has clearly improved the overall patient waiting times and reduced the number of hospital visits.

\section{Step 2: lessons and limitations}

In seeking to implement a new type of outpatient clinic approach, challenges were encountered in gaining support from colleagues, particularly as there were no comparable clinics already operating within the health board. Some colleagues had particular concerns about the efficiency of the approach and whether or not it could potentially be harmful to the patients. These concerns were addressed by detailed discussions in directorate meetings. The questionnaires and careful patient selection were important to ensure that the right patients were receiving the right care at the right time.

Another concern was that of ensuring valid consent. Valid consent is of paramount importance and has come under scrutiny following the judgement in the case Montgomery v Lanarkshire Health Board. ${ }^{18}$ Concerns were expressed as to whether there was sufficient time for patients to make a fully informed decision about treatment because in the one stop clinic the patients were to be reviewed, tested and undergo surgery all on the same day. However, to address this, the patients were carefully selected, were given detailed information explaining the one stop clinic process, received an information sheet about their diagnosis in the post and received two phone calls to ensure they were willing to be part of the one stop clinic process. On the day of the clinic, they were reviewed and had nerve conduction studies in the morning followed by surgery in the afternoon. There were a few hours in between for them to reflect on their consultation and ask questions if required.

Initially, the nerve conduction clinics did not reduce the overall waiting time from appointment to surgery, although they did reduce the time waited for nerve conduction studies. However, as time progressed, the time from appointment to surgery did improve (nerve conduction group 2). The reasons for this are unclear but may be due to the fact that as the clinics and the booking of patients into them became more organised and established, the wait times improved.

Patient opinion on the one stop clinic process was solicited. However, obtaining this feedback was a particular challenge due to their reluctance to engage in the feedback process, leading to a limited amount of feedback garnered. Addressing this issue would aid in assessing 
more detailed patient opinion of this approach and whether it was an improvement in their journey through treatment.

\section{Step 3: conclusion}

The aim of the nerve conduction and one stop clinic was to enhance the patient journey, reduce the time patients wait for treatment and reduce the number of hospital visits. The results show that this has been achieved. Completed questionnaires and verbal feedback demonstrated that patients were satisfied with their management. Additionally, some patients invited to the one stop clinic found it empowering, as they could choose whether to be a part of the process and could effectively pick the date of their procedure.

Currently, the patients attending the one stop clinics receive treatment more quickly than patients managed in the conventional way. As the system of using the one stop clinics is proving worthwhile, we believe that it should be continued. The one stop clinics are now developed, with each member of the team knowing their specific role in the process, the protocols are well established and initial concerns have been addressed. The ongoing success and continued use of this pathway indicates that it is a sustainable process.

In terms of extending the indications for the one stop clinics, other hand conditions may be amenable to inclusion. However, care needs to be taken to ensure that more complex patients and conditions are still seen in the appropriate setting, with the appropriate time allocated for detailed clinical assessment.

Contributors All authors have been active contributors to the paper.

Competing interests None declared.

Provenance and peer review Not commissioned; externally peer reviewed.

Open Access This is an Open Access article distributed in accordance with the Creative Commons Attribution Non Commercial (CC BY-NC 4.0) license, which permits others to distribute, remix, adapt, build upon this work non-commercially, and license their derivative works on different terms, provided the original work is properly cited and the use is non-commercial. See: http://creativecommons.org/ licenses/by-nc/4.0/
Published by the BMJ Publishing Group Limited. For permission to use (where not already granted under a licence) please go to http://www.bmj.com/company/ products-services/rights-and-licensing/

\section{REFERENCES}

1. Bleustein $C$, Rothschild DB, Valen A, et al. Wait times, patient satisfaction scores, and the perception of care. Am J Manag Care 2014;20:393-400.

2. Lizaur-Utrilla A, Martinez-Mendez D, Miralles-Muñoz FA, et al. Negative impact of waiting time for primary total knee arthroplasty on satisfaction and patient-reported outcome. Int Orthop 2016;40:2303-7.

3. www.wales.nhs.uk/sitesplus/866/home (accessed 22 Feb 2017).

4. Wales Audit Office. A Comparative Picture of Orthopaedic Services. Aneurin Bevan University Health Board, 2015.

5. Bulstrode C, et al. Oxford textbook of trauma and orthopedics. 2nd edn. New York: Oxford University Press, 2011.

6. http://bestpractice.bmj.com/best-practice/monograph/380/ treatment/details.html (accessed 23 Apr 2017).

7. Verdugo RJ, Salinas RA, Castillo JL, et al. Surgical versus nonsurgical treatment for carpal tunnel syndrome. Cochrane Database Syst Rev 2008;8:CD001552.

8. Leit ME, Weiser RW, Tomaino MM. Patient-reported outcome after carpal tunnel release for advanced disease: a prospective and longitudinal assessment in patients older than age 70. $J$ Hand Surg Am 2004;29:379-83.

9. Wortman M. 'See-and-Treat' hysteroscopy in the management of endometrial polyps. Surg Technol Int 2016;28:177-84.

10. Muthuveloe D, Nkwam N, Hutton P, et al. Urologist led one-stop testicular clinic: the UK 'gold standard'. Springerplus 2016;5:17227.

11. Delaloge S, Bonastre J, Borget I, et al. The challenge of rapid diagnosis in oncology: diagnostic accuracy and cost analysis of a large-scale one-stop breast clinic. Eur J Cancer 2016;66:131-7.

12. Gorman M, Coelho J, Gujral S, et al. One-stop clinic utilization in plastic surgery: our local experience and the results of a UK-wide national survey. Plast Surg Int 2015;2015:1-8.

13. Salam MA, Matai V, Salhab M, et al. The facial skin lesions 'see and treat' clinic: a prospective study. Eur Arch Otorhinolaryngol 2006;263:764-6.

14. Bermejo F. A one-stop clinic in gastroenterology - benefits and limitations. Rev Esp Enferm Dig 2016;108:1-2.

15. Trueland J. All in a day's work. An innovative one-stop clinic is keeping frail older people out of hospital. Nurs Stand 2014;28:24-5.

16. Ball C, Pearse M, Kennedy D, et al. Validation of a one-stop carpal tunnel clinic including nerve conduction studies and hand therapy. Ann R Coll Surg Engl 2011;93:634-8.

17. Reid MJ, David LA, Nicholl JE. A one-stop carpal tunnel clinic. Ann R Coll Surg Engl 2009;91:301-4.

18. New judgment on patient consent. www.medicalprotection.org/uk/ for-members/news/news/2015/03/20/new-judgment-on-patientconsent (accessed 11 Oct 2016). 